\title{
Ação do fungo Beauveria bassiana, isolado 986, sobre o ciclo biológico do cascudinho Alphitobius diaperinus em laboratório
}

\author{
Action of the fungus Beauveria bassiana, strain 986, over the biologic cycle of the Alphitobius \\ diaperinus beetle in laboratory
}

\begin{abstract}
Aleksandro Schafer da Silva ${ }^{1}$ Amanda Pífano Neto Quintal ${ }^{1}$ Sílvia Gonzalez Monteiro ${ }^{2}$ Rovaina Laureano Doyle ${ }^{3}$ Janio Morais Santurio ${ }^{4}$ Vânia Rita Elias Pinheiro Bittencourt ${ }^{5}$
\end{abstract}

\section{- NOTA -}

RESUMO

O presente trabalho foi realizado para verificar a eficácia do fungo Beauveria bassiana em todas as etapas de desenvolvimento de Alphitobius diaperinus e assim saber em que fase ele é mais susceptível ao controle biológico. O fungo B. bassiana, isolado 986, foi testado em duas concentrações $\left(3,4 \times 10^{6}\right.$ e $3,4 \times 10^{8}$ conídios $\left.\mathrm{ml}^{-1}\right)$ mais um grupo controle. Foram realizadas duas leituras, uma sete e outra quatorze dias após a aplicação dos fungos. Na concentração 3,4X10 $10^{6}, 54 \%$ dos ovos tratados estavam inférteis, ocorrendo $54 \%$ de mortalidade de larvas tratadas nos estádios I, II e III, 22,5\% nos estádios IV, V e VI, 9,5\% nos estádios VII e VIII e 24,5\% de mortalidade das pupas. Na concentração $3,4 \times 10^{8}, 66,8 \%$ dos ovos tratados estavam inviáveis, ocorrendo mortalidade de $56 \%$ das larvas tratadas nos estádios I, II e III, 34\% nos estádios IV, V e VI, 24,5\% nos estádios VII e VIII e 49,5\% das pupas. Já no grupo controle, 13,3\% dos ovos estavam inviáveis, ocorrendo mortalidade de $10 \%$ das larvas nos estádios I, II e III, $4 \%$ nos estádios IV, V e VI e 0\% de mortalidade nos estádios VII, VIII e em pupas. Sobre o cascudinho adulto, o fungo não teve efeito nocivo em nenhum grupo analisado. Com base nesses resultados, observou-se que o fungo nas concentrações testadas apresentou efeito nocivo às fases do ciclo biológico do cascudinho, com exceção do inseto adulto.

Palavras-chave: controle biológico, Alphitobius, Beauveria, avicultura.

\section{ABSTRACT}

The present research was carried out to verify the Beauveria bassiana fungus efficacy in all development phases of Alphitobius diaperinus and to know in which phase it is more susceptible for biologic control. The B. bassiana, 986isolated fungus, was tested in two different concentrations (3.4 $\times 10^{6}$ and $3.4 \times 10^{8}$ conidium $\mathrm{ml}^{-1}$ ) and a control group. Two readings were realized, one after 7 days of fungus application and the other after 14 days. At concentration of $3.4 \times 10^{6}$ conidium $m L^{-1}, 54 \%$ of treated eggs were infertile, with larva death of $54 \%$ at I, II and III phase, $22.5 \%$ at IV, V, and IV phase and $9.5 \%$ at VII and VIII phase. For pupa stage $24.5 \%$ of death was found. At concentration of $3.4 \times 10^{8}$ conidium $\mathrm{ml}^{-1}$, $66.8 \%$ of treated eggs were impracticable occurring treated larva death of $56 \%$ at I, II and III phase; $34 \%$ at IV, V and VI phase, $24.5 \%$ at VII and VIII phase and $49.5 \%$ at pupa phase. For control group, $13.3 \%$ of eggs were not viable with larva death of $10 \%$ at I, II and III phase, 4\% at IV, V and VI phase and $0 \%$ at pupa, VII and VIII phase. About the adult lesser mealworms, the fungus did not present noxious effect at all analyzed group. In conclusion, these results showed that the fungus at tested concentrations presented noxious effect at all biologic cycle phases of lesser mealworms, except for the adult insect.

Key words: biologic control; Alphitobius, Beauveria, aviculture.

${ }^{1}$ Curso de Medicina Veterinária, Universidade Federal de Santa Maria (UFSM), Santa Maria, RS, Brasil.

${ }^{2}$ Departamento de Microbiologia e Parasitologia, UFSM, Santa Maria, RS, Brasil. Faixa de Camobi, Km 9, Campus Universitário, 97105-900, Prédio 20, Sala 4232. Fax: (55) 3220 8958. E-mail: sgmonteiro@uol.com.br. Autor para correspondência ${ }^{3}$ Programa de Pós-graduação do Curso de Medicina Veterinária, UFSM, Santa Maria, RS, Brasil.

${ }^{4}$ Departamento de Microbiologia e Parasitologia, UFSM, Santa Maria, RS, Brasil.

${ }_{5}^{5}$ Departamento de Parasitologia Animal da Universidade Federal Rural do Rio de Janeiro (UFRRJ), Rio de Janeiro, RJ, Brasil. 
A. diaperinus é um inseto cosmopolita, comumente encontrado em alta densidade nos aviários. Tanto larvas como adultos são encontrados nas camas de aviários, alimentando-se de adubo, ração, aves mortas e moribundas (DESPINS et al., 1987). Esse coleóptero tem sido responsável por grandes prejuízos econômicos na avicultura, uma vez que as aves ciscam na cama para se alimentar do cascudinho, o que reduz o consumo de ração, alterando significativamente a conversão alimentar (MATIAS, 1992). Além disso, suas larvas lesionam a pele, favorecendo infecções secundárias, o que diminui a qualidade da carne (ELOWNI \& ELBIHARIS, 1979).

Este inseto é o vetor da leucose aviária, tendo sido encontrado em seu interior colônias de bactérias gram positivas e negativas como Streptococcus sp., Bacillus subtilis, Corynebacterium sp., Staphilococcus aureus, Escherichia coli, Serratia marcescens, Salmonella typhimurium, além de fungos como Aspergillus flavus e Candida sp. (DE LAS CASA et al., 1972).

O ciclo biológico do cascudinho é inconstante, depende das condições climáticas e da disponibilidade de alimento. Em temperatura de $27^{\circ} \mathrm{Ce}$ umidade relativa (UR) de $80 \%$, a eclosão das larvas ocorre em 3 a 10 dias, as quais sofrem de 6 a 10 mudas no período de 15 a 20 dias, atingindo o estádio de pupa. Estas se desenvolvem de 4 a 14 dias, quando se tornam adultos e podem viver mais de um ano. As fêmeas iniciam a postura em 6 a 10 dias após o acasalamento (PAIVA, 2000).

B. bassiana é encontrado comumente infectando insetos (ALVES, 1986) e seu uso como entomopatógeno tem uma grande vantagem sobre os pesticidas convencionais, pois persiste na população hospedeira, reduz sua longevidade e ocasiona altas taxas de mortalidade em larvas e adultos das populações de insetos (ROBERTS \& CASTILLO, 1980). Segundo SAMISH \& GLAZER (1991), o gênero Beauveria é um dos mais promissores agentes para controle biológico de artrópodes, pois é de fácil dispersão, possui grande variedade de hospedeiros e habilidade de penetrar pela cutícula.

O presente trabalho foi realizado com o intuito de verificar a eficácia do fungo B. bassiana em todas as etapas de desenvolvimento de $\boldsymbol{A}$. diaperinus e assim saber em que fase ele é mais susceptível ao controle biológico. Este experimento foi realizado no Laboratório de Parasitologia Veterinária da Universidade Federal de Santa Maria, durante os meses de dezembro de 2004 a julho de 2005. Os insetos foram coletados na cama e na ração de frangos provenientes de galpões avícolas da região de Lajeado, RS, e enviados em sacos plásticos fechados. No laboratório, houve seleção e limpeza das amostras com o objetivo de obter o coleóptero adulto e reduzir o teor de material contaminado, como penas, fezes e ração, além da presença de outros insetos.

Após a sexagem dos coleópteros adultos, 20 casais foram alojados em bandejas plásticas contendo serragem autoclavada e algodão umedecido com água destilada. Esses insetos foram alimentados com ração para coelho para manutenção de colônias e obtenção das diferentes fases evolutivas. Essas bandejas permaneceram em câmara climatizada com temperatura e umidade controladas $\left(27^{\circ} \mathrm{C}\right.$ e $80 \%$ UR).

O isolado 986 de B. bassiana, oriundo de carrapatos, foi obtido do Departamento de Entomologia da ESALQ/USP e mantido em meio BDA (Ágar Batata Dextrose) em câmara climatizada $\left(27^{\circ} \mathrm{Ce} 80 \%\right.$ UR) para desenvolvimento. A cada 15 dias, o isolado foi repicado em meio de cultura e, após três dias de crescimento, foi armazenado sob refrigeração. Não foi realizado o revigoramento da cepa por bioensaio. As cepas eram retiradas do freezer 24 horas antes dos testes e mantidas em temperatura e umidade controladas $\left(27^{\circ} \mathrm{C}\right.$ e $80 \%$ UR). A partir desses isolados, foram feitas duas diluições de esporos do fungo (ALVES, 1986) em 50ml de água destilada $\left(3,4 \times 10^{6}\right.$ e $10^{8}$ conídios $\left.\mathrm{ml}^{-1}\right)$, utilizadas para imersão das diferentes fases da população de A.diaperinus durante 15 segundos. Os bioensaios foram repetidos duas vezes para cada fase do ciclo biológico.

A seleção das diferentes fases evolutivas do cascudinho testadas seguiu a classificação de SILVA et al. (2005), baseada no tamanho da cabeça e no comprimento do corpo. Foram selecionadas 50 fases do ciclo (ovo, larva, pupa, adulto) para cada bioensaio. As suspensões dos esporos fúngicos foram utilizadas na fase de ovo, larva, pupa e adulto. Os estádios larvais foram divididos em três grupos de tratamento: Larvas A (estádios L1, L2, L3), Larvas B (estádios L4, L5, L6) e Larvas C (estádios L7 e L8). A primeira leitura foi realizada sete dias depois da aplicação do fungo e repetida 14 dias após o início do experimento. Para cada etapa do ciclo biológico de $A$. diaperinus, foi feito um grupo controle onde se utilizou água destilada para imersão.

Foram feitas análises de variância (ANOVA) para saber se houve variações dentro de um mesmo tratamento com duas concentrações diferentes de um mesmo isolado. ANOVA foi seguida por aplicação do teste de Tukey para comparação entre as médias calculando-se o coeficiente de variação para verificar a precisão dos dados (SILVA\& AZEVEDO, 2002). 
Observou-se, após sete dias da aplicação do fungo $\boldsymbol{B}$. bassiana, na concentração $3,4 \times 10^{6}$ conídios $\mathrm{ml}^{-1}$, que $54 \%$ dos ovos tratados não apresentaram eclosão de larvas. Esta concentração também causou $54 \%$ de mortalidade das larvas tratadas nos estádios I, II e III, 22,5\% nos estádios IV, V e VI e 9,5\% nos estádios VII e VIII. No estádio de pupa, a eficácia do fungo foi de $24,5 \%$. Utilizando-se a concentração $3,4 \times 10^{8}$ conídios $\mathrm{ml}^{-1}$, constatou-se que $66,8 \%$ dos ovos testados estavam inviáveis, e que a mortalidade de larvas tratadas nos estádios I, II e III, era de $56 \%$, de $34 \%$ nos estádios IV, V e VI, de $24,5 \%$ nos estádios VII e VIII e que a mortalidade de pupas era de 49,5\%. Nas duas suspensões testadas, não ocorreu mortalidade de adultos . Após análise estatística dos resultados, observou-se que as concentrações usadas na fase de ovos e larvas dos estágios L1, L2 e L3 apresentavam médias semelhantes, o que significa que os tratamentos nas duas concentrações testadas não diferem estatisticamente entre si (Figura 1).

GEDEN \& STEINKRAUS (2003) encontraram 60 a $90 \%$ de redução da fase larval em laboratório testando B. bassiana em A. diaperinus, sendo seus resultados superiores aos relatados no presente estudo, provavelmente devido à cepa do fungo utilizada, visto que a concentração do fungo e a temperatura ambiente foram semelhantes.

Neste estudo, houve sensibilidade somente das fases larvais, de pupa e de ovo do cascudinho frente ao fungo B. bassiana. Entretanto, ALVES et al. (2005), ao trabalharem isolando fungos de cadáveres de A. diaperinus semanalmente encontrados no solo de um aviário comercial, relataram que $\boldsymbol{B}$. bassiana estava presente em todas as avaliações, infectando principalmente larvas $(74,4 \%)$ e adultos $(40,7 \%)$.

Os resultados mostram que as concentrações 3,4 X $10^{6}$ e $10^{8}$ de Beauveria não tiveram efeitos sob o inseto adulto, enquanto BATISTA et al. (2003), ao avaliarem a ação de B. bassiana na concentração $10^{9}$ conídios $\mathrm{ml}^{-1}$ em larvas e adultos de A. diaperinus, observaram ação larvicida de até $17 \%$ e adulticida de $29 \%$. A baixa eficácia do fungo verificada nos testes laboratoriais com o cascudinho neste estudo e também pelo autor citado anteriormente pode estar relacionada ao tempo de contato do fungo com o coleóptero, pois Beauveria bassiana é responsável

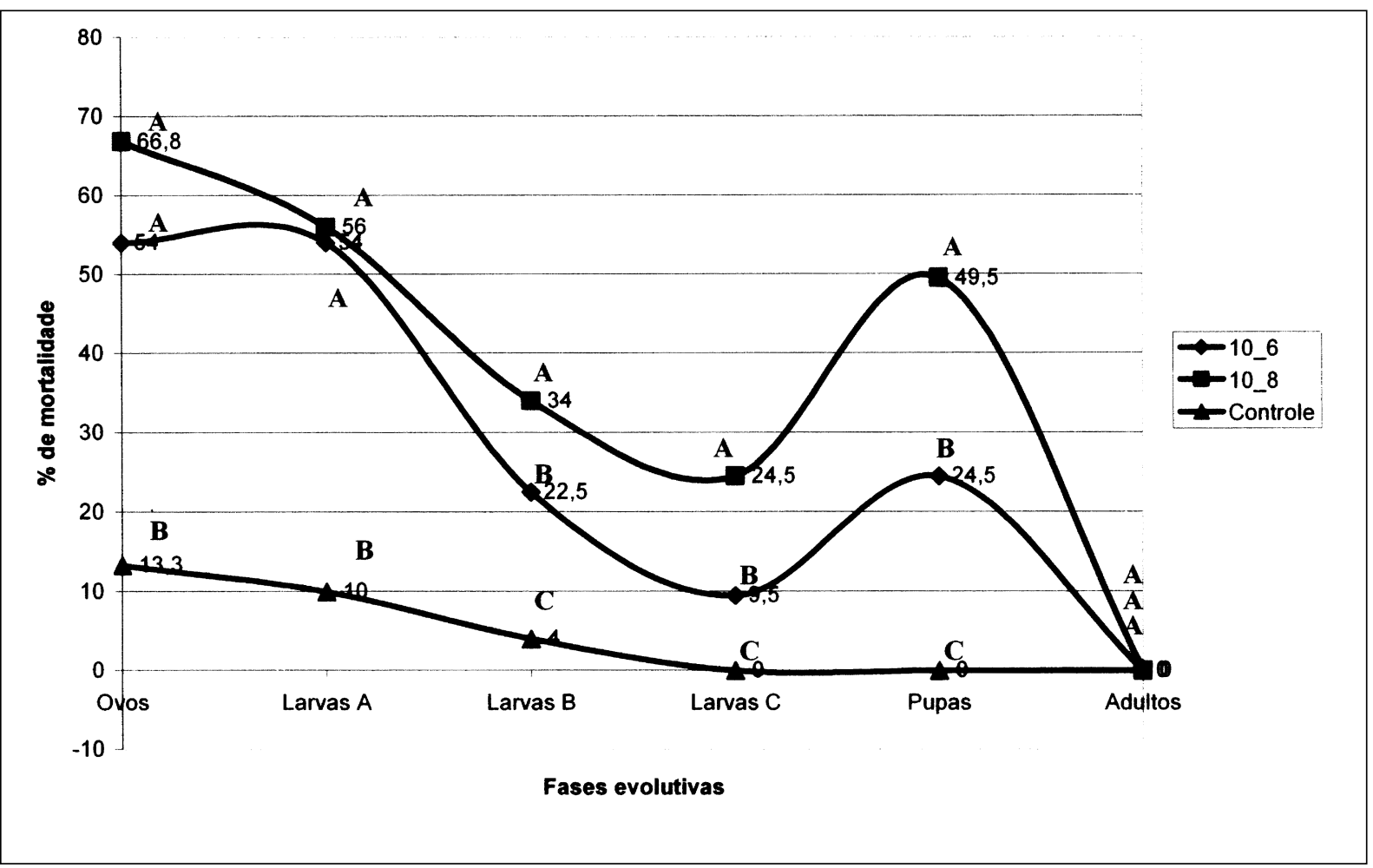

Figura 1 - Porcentagem de mortalidade das fases evolutivas de Alphitobius diaperinus em bioensaios com o fungo Beauveria bassiana do isolado 986 e comparação estatística entre os resultados de cada estádio do ciclo biológico do cascudinho.

Obs: Médias seguidas por letras iguais na mesma coluna não diferem estatisticamente entre si a $5 \%$ de probabilidade pelo teste de Tukey.

Ciência Rural, v.36, n.6, nov-dez, 2006. 
pelo controle natural do Alphitobius em aviários (ALVES et al. 2005).

ALVES et al. $(2004,2005)$ relatam a ocorrência natural de B. bassiana e M. anisopliae sobre larvas e adultos do cascudinho em aviários comerciais no Brasil, controlando a população de coleópteros. Em laboratório, 60 dias após o teste com fungo, observouse $3 \%$ de mortalidade do cascudinho adulto, dos quais tentou-se isolar o fungo $\boldsymbol{B}$. bassiana sem sucesso. Isso leva a concluir que a mortalidade do inseto não foi conseqüência do efeito nocivo do fungo.

A mortalidade dos insetos nesta pesquisa foi inferior à observada em outros trabalhos (GEDEN \& STEINKRAUS, 2003 \& GEDEN et al. 1998), fato este que pode ser devido ao isolado 986 ser obtido de carrapato, tendo este menor virulência quando isolado de espécies diferentes, como foi relatado no trabalho de GEDEN et al. (1998). Esses autores utilizaram dois isolados de Beauveria bassiana obtidos de larvas de cascudinho em infecção natural (WV) e isolado de moscas de casa (NC), obtendo maior sensibilidade do inseto ao isolado WV na concentração 2,5 X $10^{11}$ conídios $\mathrm{m}^{-2}$, sendo a eficiência de $100 \%$ para larvas.

O coleóptero adulto pode viver mais de um ano na cama das aves, o que torna difícil o seu controle, pois produtos químicos eficientes não são aconselhados por permanecerem na carne das aves, contrariando recomendações do Ministério da Saúde (PAIVA, 2000). Segundo ALVES et al. (2004), o controle biológico destaca-se como alternativa viável, uma vez que os fungos entomopatogênicos não oferecem riscos de contaminação às aves e ao produtor. Com o presente estudo, foi possível observar que o fungo pode ser uma alternativa de redução desta praga da avicultura industrial diminuindo riscos de contaminação, pois ovos, larvas nos estádios I, II, III e pupas apresentaramse susceptíveis ao efeito nocivo do fungo B. bassiana, com mais de $50 \%$ de eficácia nas concentrações testadas.

As fases susceptíveis ao fungo foram ovos, os estádios larvais I, II, III e pupa. Já a fase adulta do cascudinho não foi afetada pelo isolado 986 do fungo B. bassiana. Observou-se que quanto maior a concentração $\left(3,4 \times 10^{8}\right.$ conídios $\left.\mathrm{ml}^{-1}\right)$ do fungo $\boldsymbol{B}$. bassiana, isolado 986, maior a mortalidade do $\boldsymbol{A}$. diaperinus nas fases larvais IV, V, VI, VII, VIII e em pupas do ciclo biológico. Já as fases de ovo e de larvas do estádio I, II, III não diferiram comforme os resultados do tratamento nas concentrações testadas.

\section{REFERÊNCIAS}

ALVES, S.B. Controle microbiano de insetos. São Paulo: Manole, 1986. 407p.
ALVES L.F.A. et al. Ocorrência natural de Beauveria bassiana (Bals.) Vuilleman (Moniliales: Moniliaceae) sobre o cascudinho Alphitobius diaperinus (Panzer) (Coleoptera: Tenebrionidae), em aviário comercial de Cascavel, PR. Neotropical Entomology, v.34, n.3, p.507-510 2005

ALVES L.F.A. et al. Ocorrência de Metarhizium anisopliae (Metsch) Sorok. em adultos de cascudinho (Alphitobius diaperinus) (Panzer) (Coleoptero: Tenebrionidae) em aviário comercial em cascavel, PR. Neotropical Entomology, v.33, n.6, p.793-795, 2004

BATISTA J.S.S. et al. Influencia do meio de cultivo na virulência de isolados do fungo entomopatogênico Beauveria bassiana (Bals.) Vuil. In: SEMANA DE BIOLOGIA, UNIOESTE CAMPUS, 18., 2003, Cascavel, PR. Anais... Cascavel: Unioeste, 2003. V.18

DE LAS CASA, E. et al. Bacteria and fungi within the lesser mealworm collected from poultry brooder houses. Environmental Entomology, v.1, n.1, p.27-30,1972.

DESPINS, J.L. et al. Contructions profiles of hing rise caged layer houses in associantion with insulation damage caused by the lesser mealworm. A. diaperinus in Virginia. Poultry Science, v.66, p.243-250, 1987.

ELOWNI, E.E.; ELBIHARIS, S. Natural and experimental infection of the beetle Alphitobius diaperinus with choanotaenia infundibulum and other chicken tapeworms. Veterinary Science Communications, v.3, p.171-173, 1979.

GEDEN, C.J. Laboratory Evaluation of Beauveria bassiana (Moniliales: Moniliaceae) against the Lesser Mealworm, Alphitobius diaperinus (coleoptera: Tenebrionidae) in Poultry Litter, Soil, and a pupal Trap. Neotropical Entomology, v.27, n.1, p.71-77, 1998.

GEDEN, C.J.; STEINKRAUS, D.C. Evaluation of three formulations of Beauveria bassiana for control of lesser mealworm and hide beetle in Georgia poultry houses. Journal of Economic Entomology, v.96, p.1602-1607, 2003.

MATIAS, R.S. Controle Alphitobius diaperinus em piso de cama de aviários. Pesquisa Agropecuária Brasileira, v.27, p.205-207, 1992.

PAIVA, D.P. Controle de moscas e cascudinhos. Desafios na produção agrícola. In: SIMPÓSIO SOBRE RESÍDUOS DA PRODUÇÃO AVÍCOLA, 2000, Concórdia, SC. Anais... Concórdia: Embrapa de Suínos e Aves, 2000.

ROBERTS, D.W.; CASTILLO, J.M. Bibliography on pathogens of medically important arthropods. Bullitin World Health Organization, v.58, p.190-197, 1980.

SAMISH, M.; GLAZER, J. Killing ticks with parasitic nematodes of insects. Journal Inverted Pathology, v.58, p.281-282, 1991.

SILVA A.S. et al. Ciclo biológico do cascudinho Alphitobius diaperinus em laboratório. Acta Scientiae Veterinariae, v.33, n.2, p.177-181, 2005

SILVA, F.A.S.; AZEVEDO, C.A.V. Versão do programa computacional Assistat para o sistema operacional Windows. Revista Brasileira de Produtos Agroindustriais, v.4, n.1, p.71-78, 2002. 